\title{
Fundamentals point to carbon capture
}

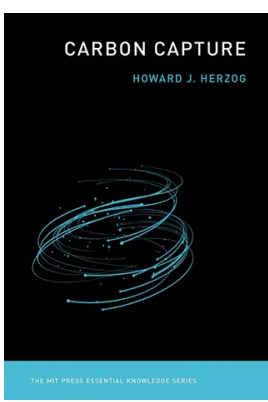

Carbon Capture

By Howard J. Herzog

MIT Press: 2018. 216 PP E11.95

n 2005, the Intergovernmental Panel on Climate Change published a Special Report on carbon dioxide capture and storage (CCS). The model results available at the time suggested that, "use of CCS in conjunction with other measures could significantly reduce the cost of achieving stabilization and would increase flexibility in achieving these reductions" ${ }^{\text {. }}$. Today, energy system modellers interested in finding cost effective pathways to tackling climate change consistently confirm this conclusion. In Carbon Capture, Howard J. Herzog provides a comprehensive, but succinct, introduction to CCS covering the topics that are essential for understanding if, and how, CCS can do what the models suggest.

Carbon Capture lays out Herzog's perspective on the current state of the art methods, presenting an accessible introduction to the range of technology that may be encountered in the field, alongside the broader context (ranging from climate change science to policy and politics) in which CCS is developed and deployed. The analysis is rigorous but the presentation is clear - and only a minimal previous knowledge of the relevant underpinning science is assumed. Each chapter includes well-chosen examples to aid understanding, and a useful bibliography.

Herzog argues that CCS is a "promising but overlooked climate change mitigation pathway". Public awareness of CCS remains relatively low and many policymakers are yet to be fully convinced of its value. Arguably, one of the most significant challenges (and opportunities) for CCS is that it is not one solution, but several. Much of the early focus of CCS research and development was targeted at coal-fired power generation. Today, there is increasing interest in the role CCS could play in significantly reducing $\mathrm{CO}_{2}$ emissions from a wider range of fuels (for example, natural gas, biomass and waste-derived fuel) and other large industrial sources (for example, refineries, steel-making and cement production).

A chapter is devoted to 'negative emissions technologies' that remove $\mathrm{CO}_{2}$ from the atmosphere, either directly or by using biomass-enhanced CCS. There is "considerable disagreement" about the role that these technologies can and should play. If we are able to remove significant amounts of $\mathrm{CO}_{2}$ from the atmosphere it could be a game changer in responding to global climate change. Herzog is concerned though, that "more and more people are embracing this concept because it excuses pushing hard policy decisions regarding emissions reductions down the road".

CCS implementation uses a wide variety of technologies and draws on a broad range of science. There are several options for $\mathrm{CO}_{2}$ capture. To be effective for climate change mitigation, the main criteria is that captured $\mathrm{CO}_{2}$ remains out of the atmosphere for a thousand years or more. Thus, in general, "geologic storage of $\mathrm{CO}_{2}$ is the mirror image of oil and gas production". $\mathrm{CO}_{2}$ is injected into porous geologic formations deep under the Earth's surface, where four different trapping processes (structural, capillary, solubility and mineral) ensure that it stays there.

CCS is unique because its primary purpose is to tackle climate change. Although the constituent technologies typically are not new, Herzog suggests that integrated CCS $\left(\mathrm{CO}_{2}\right.$ capture, transport and storage) is currently the "new kid on the block" in energy policy.

Economists generally agree that 'market pull' (typically putting a price on $\mathrm{CO}_{2}$ and, hence, creating a market for CCS) should be the most cost-effective approach, but this requires widespread political agreement to introduce and sustain a sufficiently robust $\mathrm{CO}_{2}$ price. 'Technology push' policies are also an option (for example, tax credits in the United States and government-backed competitions in the United Kingdom). Although they are sometimes viewed as inefficient, they have the benefit that support can be tailored specifically to encourage the development and deployment of particular technologies.

The broad range of technology and policy considerations is, of course, also a challenge for anyone writing an introduction to CCS - particularly one intended to be a concise introduction for non-specialists - but
Herzog rises to the challenge. He provides a comprehensive, yet clear, narrative, touching on all the themes that matter in understanding the current state of play for CCS and its potential for the future.

In fact, Carbon Capture can be seen as a series of introductory lectures for a general audience. There is a careful balance between personal reflection and providing relevant factual information, typical of a high-quality public lecture. For me, it is the perfect text to recommend to my more experienced students as they look to grasp the technical fundamentals of options like CCS without needing to engage with a full textbook.

It should also be essential reading for anyone curious about why modelling studies have repeatedly suggested that CCS should be part of global efforts to decarbonise our economies at an affordable cost. Herzog does not provide a detailed review of this literature, although as he looks to the future he does refer to work by the International Energy Agency, which concluded that "without CCS, the transformation of the power sector will be at least USD 3.5 trillion more expensive" 2 .

Overall, Carbon Capture achieves Herzog's aim of helping people understand what carbon capture is all about. He provides a comprehensive but accessible introduction to key technologies that are globally relevant. This is complemented by insightful review, a useful introduction to key projects where carbon capture can be seen in action today, and analysis of key motives for developing and implementing CCS. What remains to be seen is whether CCS can move beyond its status as a "promising but overlooked" option for climate change mitigation, to become a significant contributor in reducing global $\mathrm{CO}_{2}$ emissions.

Reviewed by Hannah Chalmers School of Engineering, The University of Edinburgh, Edinburgh, UK.

e-mail:Hannah.Chalmers@ed.ac.uk

Published online: 26 April 2019

https://doi.org/10.1038/s41558-019-0462-4

\footnotetext{
References

1. IPCC Special Report on Carbon Dioxide Capture and Storage (eds Metz, B., Davidson, O., de Coninck, H., Loos, M. \& Meyer, L.) 21 (Cambridge Univ. Press, 2005).

2. 20 Years of Carbon Capture and Storage: Accelerating Future Deployment (OECD \& IEA, 2016).
} 